\title{
Postmenopausal women in gynecological care
}

\author{
Magdalena Pertyńska-Marczewska ${ }^{1}$ Tomasz Pertyński² \\ 1Private Practice, London, United Kingdom \\ ${ }^{2}$ Faculty of Health Science, Mazovian Public University in Plock, Poland
}

\begin{abstract}
Menopause is one of the most important events in the female reproductive life cycle, being a transition from the reproductive to the nonreproductive stage. It is a milestone that may have a negative influence on quality of life and one that brings in several physiological changes that affect the life of a woman permanently. According to a Polish epidemiological forecast, in 2050 the average female life expectancy will be 87.5, which is 6.4 years longer than today. Thus, the life expectancy of women who will be 60 or older in 2050 will also extend. Therefore, strategies need to be optimized to maintain postreproductive health, in part because of increased longevity. The general gynecologist can expect to see more elderly female patients as the population continues to age. Office management of the gynecologic problems of geriatric women requires sensitivity to the special needs of this group. Nowadays, most women spend more than one-third of their lives after menopause; therefore there is plenty of opportunity for gynecologists to cater to the needs of postmenopausal women. It is in their scope of practice to help postmenopausal women through "healthy aging". In this review we look into screenings, early identification, lifestyle modifications and appropriate intervention that may prevent many chronic conditions that cause morbidity and mortality during the postmenopausal years.
\end{abstract}

Key words: postmenopause, screening, healthy aging.

\section{Introduction}

Menopause is defined as the last menstrual period followed by no menstruation for the next 12 months with no pathological causes of such a condition identified. Menopause is one of the most important events in the female reproductive life cycle, a transition from the reproductive to the nonreproductive stage.

This introduces several physiological changes that affect a woman's further life permanently, setting the stage for aging $[1,2]$.

In the United States, the median age at which menopause occurs is 52, but it can vary between 40 and 58 years of age [3]. The mean age of the onset of natural menopause in Polish population is 51.25 [4]. Over the last 25 years, a slowdown in demographic development in Poland and significant changes in the age structure of its inhabitants have been observed. At the end of 2014, the population of Poland reached 38.5 million, including over 8.5 million people aged 60 and above (over 22\%). Among the elderly population, the majority are women (59\%). Life expectancy for people aged 60 has also increased over the past 23 years. The life expectancy of 60-year-olds has extended by 4.1 years for men and 4.5 for women since 1991. According to an epidemiological forecast, in 2050 the average female life expectancy will be 87.5 , which is 6.4 years longer than today. Thus, the life expectancy of people who will be 60 or older in 2050 will also extend [5].

A report by the Population Reference Bureau estimated that 40 million people in the U.S. are 65 or older - a number that is expected to reach 89 million by 2050 [6] - and by the year 2025, the number of postmenopausal women is expected to rise to 1.1 billion worldwide [7]. These changing demographics raise the problem of providing gynecologic care for these women and the issue of the role of the gynecologist as their primary care physician [8], since as experts in women's health care, gynecologists are uniquely trained to guide, counsel, diagnose, and treat women across their entire lifetime [9]. It is in their scope of practice to help postmenopausal women through "healthy aging".

Healthy aging includes survival to old age, delay of the onset of non-communicable diseases and optimal functioning for a maximal period at individual levels of cells and body systems [7].

An annual "well-woman" visit provides an excellent opportunity to counsel patients about maintain- 
ing a healthy lifestyle and minimizing health risks. The periodic well-woman care visit should include screening, evaluation, and counseling [9].

\section{Preventive care recommendations}

Screenings, early identification, lifestyle modifications and appropriate intervention may prevent many chronic conditions that cause morbidity and mortality during the postmenopausal years [10].

\section{Osteoporosis screening}

Osteoporosis is characterized by low bone mass, structural deterioration, and porous bone, which are associated with higher fracture risk [11]. Bone loss, related to declining estrogen levels, increases fracture risk in postmenopausal women, who make up the majority of osteoporosis cases [12]. For example, the aging U.S. population is predicted to contribute to as much as a $50 \%$ increase in prevalence by 2025 [13]. Therefore, early detection and treatment of high-risk patients with antiresorptive medications [11], and optimization of bone health throughout life can help prevent osteoporosis.

Worldwide, osteoporosis causes more than 9 million fractures a year, meaning there is a fragility fracture every $3 \mathrm{~s}$ [14]. In just the 6 largest European countries the total number of fragility fractures is estimated to increase from 2.7 million in 2017 to 3.3 million in 2030, an increase of $23.3 \%$ [15]. About one-tenth of women in their 60s, one-fifth of women in their 70s, two-fifths of women in their 80s and two-thirds of women in their 90s have osteoporosis and an increased risk of fragility fracture [16].

In the general Polish population, over 2 million people over the age of 50 (every third woman and every fifth man) suffer from osteoporosis, in the majority of the cases, complicated by fracture [17].

It is important to remember that fractures at the hip and vertebrae are among the most common and serious sites of osteoporotic fracture. Fragility fractures of the humerus, forearm, ribs, tibia (in women, but not including ankle fractures), pelvis and other femoral fractures after the age of 50 are fractures associated with low BMD [18].

Created in 1984, the U.S. Preventive Services Task Force (USPSTF) is an independent group of national experts in prevention and evidence-based medicine that works to improve the health of all Americans by making evidence-based recommendations about clinical preventive services such as screenings, counseling services, or preventive medications.

Guidelines from the USPSTF recommend screening for osteoporosis with bone measurement testing to prevent osteoporotic fractures.
Diagnostic and treatment criteria for osteoporosis rely on hip and lumbar spine dual-energy X-ray absorptiometry measurements (DXA). The guidelines state that dual-energy X-ray absorptiometry screening is recommended for women 65 years and older, and the USPSTF endorsed use of the Fracture Risk Assessment Tool FRAX to identify screening candidates among younger postmenopausal women aged 50 to 64 years. The recommended threshold score is $9.3 \%[19,20]$.

DXA provides measurement of bone mineral density (BMD), and most treatment guidelines use central DXA to define osteoporosis and the threshold at which to start drug therapies to prevent osteoporotic fractures.

The major change in the current recommendation is that the USPSTF expanded its consideration of evidence related to fracture risk assessment, with or without BMD testing [20]. For women 65 and older, the USPSTF found convincing evidence that screening can detect osteoporosis and that treatment of women with osteoporosis can provide at least a moderate benefit in preventing fractures. For postmenopausal women younger than 65 who are at increased risk of osteoporosis, the USPSTF found adequate evidence that screening can detect osteoporosis and that treatment provides a moderate benefit in preventing fractures [20].

In addition to adequate calcium and vitamin $D$ intake and weight-bearing exercise, multiple drug therapies are approved to reduce fracture risk, including bisphosphonates, parathyroid hormone, raloxifene, and estrogen [20]. According to the USPSTF, effective fall prevention measures include weight-bearing exercise and balance training three times per week, muscle strengthening twice per week, and 150 minutes per week of moderate-intensity or 75 minutes per week of vigorous-intensity aerobic physical activity. With a revised scope of review, as well as newer evidence from trials reporting no benefit, the USPSTF found that vitamin D supplementation has no benefit in fall prevention in community-dwelling older adults not known to have vitamin D deficiency or insufficiency. Thus, the USPSTF now recommends against vitamin $D$ supplementation for the prevention of falls in community-dwelling older adults [20]. However, The National Institute on Aging recommends vitamin $D$ supplementation of at least 800 IU per day for persons with vitamin D deficiency or who are at increased risk for falls [21].

\section{Cardiovascular disease screening}

Cardiovascular disease (CVD) is the leading cause of death and disability in women older than 50, exceeding the number of deaths from malignant neoplasms, diabetes mellitus, and chronic lower respiratory diseases combined [22]. The prevalence of CVD increases rapidly at the onset of menopause and continues to increase through the post-menopausal period [10]. 
Periodic cardiovascular risk assessment in postmenopausal women can identify risk factors and enable implementation of risk reduction strategies [10, 23]. The 2019 American College of Cardiology/American Heart Association (ACC/AHA) guideline recommends using the pooled cohort risk assessment equations (http:// tools.acc.org/ASCVD-Risk-Estimator/) every three to five years to calculate the 10-year risk of atherosclerotic cardiovascular disease (ASCVD), including myocardial infarction and stroke [24].

Since 2008 the USPSTF has strongly recommended routinely screening women 45 and older for lipid disorders and treating abnormal lipid levels in persons who are at increased risk of coronary heart disease (CHD). Screening for diabetes with fasting plasma glucose is indicated for women with risk factors for CHD, such as hypertension and hyperlipidemia [25].

The ACC/AHA recommend that all adults should consume a healthy diet that emphasizes the intake of vegetables, fruits, nuts, whole grains, lean vegetable or animal protein, and fish, and minimizes the intake of trans fats, red meat and processed red meats, refined carbohydrates, and sweetened beverages. For overweight and obese adults, counseling and caloric restriction are recommended for achieving and maintaining weight loss [24].

In 2015 the USPSTF issued an update to the 2008 recommendation statement in which the USPSTF recommended screening for diabetes in asymptomatic adults with hypertension (defined as sustained blood pressure of >135/80 $\mathrm{mm} \mathrm{Hg}$ ). New evidence led the USPSTF to conclude that there is a moderate net benefit to measuring blood glucose in adults who are at increased risk for diabetes [26]. Additionally, data suggest that smoking cessation after an $\mathrm{Ml}$ and treatment of hypertension and hyperlipidemia lower the risk for CHD events in women [27].

The USPSTF and ACC/AHA recommend aspirin and statins for primary prevention of CVD in selected highrisk patients who are at low risk of adverse effects from these medications $[28,29]$.

\section{Cancer screening}

\section{Breast cancer}

There is consistency across multiple organizational guidelines that average-risk women benefit from screening mammography at least every other year from 50 to 74 years of age [30]. The evidence that screening reduces mortality from breast cancer is strongest for women 50 to 69 years of age. There is no evidence of benefit for women older than 75 years, but the USPSTF recommends screening women older than 70 years who have a reasonable life expectancy [31].

The USPSTF concludes that while there are risks associated with mammography, the benefit of screening mammography outweighs the harms by at least a moderate amount from age 50 to 74 years and especially for women in their 60s. For women in their 40s, the benefits still outweigh the harms, but to a smaller degree; this balance may therefore be more subject to individual values and preferences than it is for older women [32]. On the other hand, the American Cancer Society recommends performing mammography annually in women 45 to 54 years of age, biennially in women 55 years and older, and to not screen women with a life expectancy of less than 10 years [30].

Additionally, the American College of Obstetricians and Gynecologists recommends a mammography annually beginning at 40 years of age [33].

In recent years, a newer type of mammogram called digital breast tomosynthesis (commonly known as three-dimensional [3D] mammography) has become much more common, although it is not available in all breast imaging centers. Many studies have found that 3D mammography appears to reduce the likelihood of being called back for follow-up testing. It also appears to reveal more breast cancers, and several studies have shown that it can be helpful for women with denser breasts [34].

The USPSTF recommends that clinicians offer to prescribe risk-reducing medications, such as tamoxifen, raloxifene, or aromatase inhibitors, to women who are at increased risk for breast cancer and at low risk for adverse medication effects [35]. Based on expert opinion, the American Cancer Society and the National Comprehensive Cancer Network include aromatase inhibitors, exemestane, or anastrozole as additional options [36].

In Poland, breast cancer is the most common malignancy in women (17 379 cases in 2014; standardized incidence rate 51.6/100,000 [37]) and the second cause of death due to cancer among Polish women [37].

The recommendations of the Polish Gynecological Society (23.2.2005) state that every woman between 45 and 50 year of age should have a mammography performed every 2 years. From the age of 50 the mammography should be performed annually. Additionally, the experts pointed out that the breast ultrasound is not an examination that replaces mammography but is a supplementary part of the diagnostic process.

\section{Cervical cancer}

In the elderly population, cancer is one of the predominant causes of mortality and morbidity, and its incidence increases with ageing. Sixty percent of all cancers and $70 \%$ of cancer-related deaths occur in patients aged 65 years and over [38].

In patients aged 65 and over, cervical cancer has mortality rates ranging between 40 and $50 \%$. However, there is evidence that regular screening reduces cervical cancer risk at a rate of $80 \%$ and early detection through routine Papanicolaou (Pap) testing and treatment of precursor cervical intraepithelial neoplasia can lower mortality from cervical cancer $[39,40]$. 
According to American Cancer Society recommendations, screening tests for cervical cancer should be initiated within the first 3 years from the first sexual intercourse or at most at the age of 21. Every year obstetric examination and a Pap smear test should be performed. If the last successive 3 screening test results are within normal limits, then screening tests can be done every 2-3 years. Postmenopausal women should receive human papillomavirus and cytology co-testing every five years, or cytology alone every three years, until the age of 65 years [41]. If the last 2 tests yield negative results, screening should be stopped when the patient reaches 65 years of age. Once screening has stopped, it should not resume in women older than 65 years, even if they report having a new sexual partner [42].

Screening should be discontinued in women who undergo total hysterectomy for benign disease [42].

Additionally, shared guidelines from the American Cancer Society, American Society for Colposcopy and Cervical Pathology, and the American Society for Clinical Pathology (ACS/ASCCP/ASCP) state that routine screening should continue for at least 20 years after spontaneous regression or appropriate management of a precancerous lesion, even if this extends screening past age 65 years.

In 2018, the USPSTF updated its screening guidelines [42]. In addition to continuing to recommend triennial cytology (Papanicolaou tests) for women aged 21 to 29 years followed by either continued triennial cytology or adding a test for high-risk types of HPV every 5 years from ages 30 to 65 years, the USPSTF endorsed a strategy of hrHPV testing alone every 5 years for women aged 30 to 65 years. The USPSTF stated that referring all women with abnormal test results directly for colposcopy would lead to a much greater number of colposcopies, but it did not recommend any particular triage strategy for women with a positive test result for hrHPV; the Society of Gynecologic Oncology recommends triaging these women with HPV genotyping (tests for HPV types 16 or 18) [43].

\section{Endometrial cancer and intrauterine pathologies}

Endometrial cancer is the most common gynecolog ic cancer in developed countries and accounts for nearly $5 \%$ of cancer cases and more than $2 \%$ of deaths due to cancer in women worldwide [44].

Between 4 and $11 \%$ of postmenopausal women will experience postmenopausal bleeding (PMB) [45], accounting for approximately two-thirds of all gynecologic visits among perimenopausal and postmenopausal women [46]. However, the risk of endometrial cancer in women with PMB varies widely in individual studies from 3 to $25 \%$ [47].

The most common causes of uterine bleeding in postmenopausal women are benign and include vaginal or endometrial atrophy, cervical polyps, and submucosal fibroids [45].
In many European countries, guidelines recommend transvaginal ultrasound (TVUS) as the first-line approach in evaluation of postmenopausal bleeding, with histologic assessment indicated for women with a thickened endometrium based on cutoffs ranging from 3 to $5 \mathrm{~mm}[46,48]$.

In the United States, evaluation of PMB begins with a screening TVUS [49]. Findings of an endometrium of $\leq 4 \mathrm{~mm}$ on TVUS indicate a low likelihood of the presence of endometrial cancer, and treatment for atrophy or changes to the hormone replacement therapy regimen constitute reasonable first-line management; endometrial biopsy is not recommended [50].

However, because rare cases of endometrial carcinoma (particularly type II) can present with an endometrial thickness of less than $3 \mathrm{~mm}$, persistent or recurrent uterine bleeding should prompt a histologic evaluation of the endometrium regardless of endometrial thickness [49].

For patients with persistent $\mathrm{PMB}$ or thickened endometrium $\geq 4 \mathrm{~mm}$ on TVUS, biopsy sampling of the endometrium should be performed.

A negative tissue biopsy result in women with $\mathrm{PMB}$ is not considered to be an endpoint, and further evaluation with hysteroscopy to evaluate for focal disease is imperative. The results of endometrial biopsy are only an endpoint to the evaluation of PMB when atypical hyperplasia or endometrial cancer is identified $[49,50]$.

Hysteroscopy is confirmed as the gold standard in the assessment of abnormal uterine bleeding in menopause, permitting the elimination of false-negative results of blind biopsy through direct visualization of the uterine cavity and the performance of targeted biopsy in case of doubt [51]. It permits full visualization of the endocervix, endometrial cavity and tubal ostia, allowing visual diagnosis of focal endometrial lesions that are missed with endometrial sampling, TVS or saline infusion sonohysterography [51].

Two types of the procedure are generally performed: diagnostic and operative hysteroscopy. Diagnostic hysteroscopy allows visualization of the endocervical canal, endometrial cavity, and fallopian tube ostia. Operative hysteroscopy incorporates the use of mechanical, electrosurgical, or laser instruments to treat intracavitary pathology, thus offering a "see-andtreat" approach [52].

Advances in technology have led to miniaturization of high-definition hysteroscopes without compromising optical performance, thereby making hysteroscopy a simple, safe and well-tolerated office procedure. The new surgical technology such as bipolar electrosurgery, endometrial ablation devices, hysteroscopic sterilization, and morcellators has revolutionized this surgical modality [53]. The modern development of hysteroscopy transformed the approach to intrauterine pathologies from a blind procedure under general anesthesia 
to an outpatient procedure performed under direct visualization, offering a comprehensive diagnosis and management approach [45].

\section{Colorectal cancer}

The stage at which colorectal cancer is detected has a substantial effect on survival. The five-year survival rate is approximately $91 \%$ with localized disease but drops to $6 \%$ among individuals presenting with distant metastasis [54].

Colorectal cancer has a male predominance and is strongly associated with age; $80 \%$ of new cases occur in patients aged over 60 . Obesity and limited exercise are strong risk factors. Diets low in fruit and vegetables and fiber and high in red meat have also been associated with an increased risk. Patients with one first-degree relative under 45 or two first-degree relatives of any age who developed colorectal cancer have an approximate lifetime risk of developing the disease of $16-25 \%$ in men and $10-15 \%$ in women. Having one first-degree relative who developed the disease after the age of 65 barely increases lifetime risk. Patients with ulcerative colitis and Crohn's colitis also have an increased lifetime risk of colorectal cancer [55].

The American Cancer Society 2018 guideline for colorectal cancer screening recommends that average-risk adults aged 45 years and older undergo regular screening with either a high-sensitivity stool-based test or a structural (visual) examination, based on personal preferences and test availability. As a part of the screening process, all positive results on non-colonoscopy screening tests should be followed up with timely colonoscopy [56].

The USPSTF recommends screening for colorectal cancer beginning at 50 years of age and continuing through 75 , then individualized decision making in patients 76 to 85 years of age [57]. High-risk women who may require more intensive screening and/or genetic testing include those with a history of genetic disorders (e.g., familial adenomatous polyposis), inflammatory bowel disease, or a previous adenomatous polyp or colorectal cancer [57].

\section{Sexually transmitted diseases screening}

Older women are often sexually active, but physicians caring for older women rarely address sexual concerns. Although women's desire for sex declines with age, a majority of older women rate sex as having importance in their lives [58].

For example, in England, approximately $7 \%$ of new sexually transmitted disease (STD) diagnoses in 2018 were among individuals aged $45-64$ years [59]. According to American data from 2005, an estimated $65 \%$ of women 51 to 64 years of age engage in sexual intercourse at least once per week [60].
In a brand new British paper [61] the authors stated that the identified barriers to STD risk prevention among midlife adults include low knowledge about STDs, prioritization of intimacy above STD risks in new relationships, [62] stigmatization of STDs among older adults [62], and reduced motivation to consider safer sex following removal of pregnancy risk due to menopause or permanent contraception [63]. Interestingly, one American study found that $1 \%$ of widowed women 67 to 99 years of age developed an STD during a nineyear study [64].

The USPSTF recommends that high-risk sexually active women receive intensive behavioral counseling to reduce STD risk, and annual screening for chlamydia, gonorrhea, syphilis, and human immunodeficiency virus (HIV) infection [65].

\section{Genitourinary syndrome}

The genitourinary syndrome of menopause (GSM) is a term that describes various menopausal symptoms and signs including not only genital symptoms (dryness, burning, and irritation) and sexual symptoms (lack of lubrication, discomfort or pain, and impaired function) but also urinary symptoms (urgency, dysuria, and recurrent urinary tract infections) [66].

A majority of women suffering from GSM are of older age, with $50-70 \%$ of postmenopausal women being symptomatic at least to some degree [67].

Unlike other menopausal symptoms, GSM is a chronic, progressive condition of the vulvovaginal and lower urinary tract [68]. According to the newest statement from the North American Menopause Society (NAMS), GMS affects approximately 27 to $84 \%$ of postmenopausal women and can significantly impair health, sexual function, and quality of life [69].

These symptoms are directly related to the reduced circulating estrogen levels after menopause. Estrogen receptors (ERs; both and ) are present in the vagina, vulva, musculature of the pelvic floor, endopelvic fascia, urethra, and bladder trigone during reproductive life; their levels decline with menopause and may be restored by estrogen treatment [70]. As a result of estrogen deficiency after menopause, anatomic and histologic changes occur in female genital tissues, including reduction in the content of collagen and hyaluronic acid and in the levels of elastin, thinning of the epithelium, alterations in the function of smooth muscle cells, increase in the density of connective tissue, and fewer blood vessels. These changes reduce elasticity of the vagina, increase vaginal $\mathrm{pH}$, lead to changes in vaginal flora, diminish lubrication, and increase vulnerability to physical irritation and trauma [70].

The NAMS noted that GSM is likely underdiagnosed and undertreated, but in most cases, symptoms can be effectively managed. The diagnosis and evaluation 
of GSM are clinical and mostly established through a thorough medical history and physical pelvic examination [71].

Additionally, two instruments of measurement properties of patient-reported outcome measures specific for genitourinary symptoms (the Vulvovaginal Symptoms Questionnaire and the Day-to-Day Impact of Vaginal Aging (DIVA) Questionnaire) have been shown to be valid after a thorough assessment. These two tools can be efficiently used for the evaluation of GSM symptoms and measurement of their impact on the QOL of patients [72, 73].

A number of over-the-counter and government-approved prescription therapies available in the United States and Canada demonstrate diverse effectiveness, depending on the severity of symptoms. These include vaginal lubricants and moisturizers, vaginal estrogens and dehydroepiandrosterone (DHEA), systemic hormone therapy, and the estrogen agonist/antagonist ospemifene. Low-dose vaginal estrogens, vaginal DHEA, systemic estrogen therapy, and ospemifene are effective treatments for moderate to severe GSM. When low-dose vaginal estrogen or DHEA or ospemifene is administered, a progestogen is not indicated; however, endometrial safety has not been studied in clinical trials beyond 1 year. There are insufficient data at present to confirm the safety of vaginal estrogen or DHEA or ospemifene in women with breast cancer; management of GSM should consider the woman's needs and the recommendations of her oncologist [69].

Additionally, because of the insufficient number of placebo-controlled trials of energy-based therapies, including laser, the NAMS cannot draw conclusions on efficacy and safety or make treatment recommendations [69].

\section{Urinary incontinence and urinary tract infections}

The female genital tract and lower urinary tract share a common embryonic origin, both arising from the urogenital sinus. As estrogen plays an important role in the function of the lower urinary tract throughout the premenopausal period, estrogen deficiency after menopause causes lower urinary tract symptoms, such as dysuria, urgency, frequency, nocturia, urinary incontinence (UI), and urinary tract infection (UTI) [74]. According to various sources, $\mathrm{UI}$ is present in $30-60 \%$ of perimenopausal and postmenopausal women [75].

Irrespective of the volume, any kind of involuntary urination is defined as $\mathrm{UI}$ [76]. In particular, urge UI is more prevalent after menopause than before, and its prevalence increases with time in women with estrogen deficiency [77]. Early detection and individually tailored pharmacologic (e.g., estrogen therapy, selective estrogen receptor modulator, synthetic steroid, oxytocin, and DHEA) and/or nonpharmacologic (e.g., laser therapies, moisturizers and lubricants, homeopathic remedies, and lifestyle modifications) treatment is cardinal for not only improving quality of life but also for preventing exacerbation of symptoms in women with this condition [78].

All guidelines recommend a trial of conservative treatment before invasive therapy. These conservative therapies include behavioral therapy, physical therapy, and scheduled voiding as well as smoking cessation (smoking has been linked with an increase in estrogen metabolism leading to vaginal atrophy [79]) and caffeine abstinence. The European Association of Urology (EAU) clarifies that caffeine reduction (Level 2 evidence) improves urgency and frequency, but not UI [80, 81].

The EAU supports the use of containment devices and recommends disposable pads for light UI (Grade A), and pads, external devices, and catheters for moderate-to-severe UI (Grade A), with attention paid to balancing benefits and harms of each [81, 82].

In obese women, the Canadian Urological Association gives a Grade A recommendation for weight loss as an intervention, and the EAU recommends > 5\% weight loss as a treatment plan (Grade A) [81, 83].

The incidence of UTI rises dramatically in elderly women. Studies have shown that 15 to $20 \%$ of women aged 65 to 70 and 20 to $50 \%$ of women aged $>80$ have bacteriuria [84]. In the low-estrogen state, the normally predominant lactobacilli diminish due to decreased vaginal-epithelial glycogen. Lactobacilli, via anaerobic metabolism of glycogen, normally produce lactic acid and hydrogen peroxide. These are both essential in maintaining an acidic and hostile vaginal environment to $E$. coli and other potentially uropathogenic organisms [85].

$\mathrm{UI}$, anatomic changes such as a cystocele, increased residual urine and diabetes are the risk factors for recurrent UTI in older women [86]. Lack of awareness of the association between recurrent UTIS and GSM may result in multiple unnecessary courses of antibiotic therapy, antibiotic prophylaxis, and altered patterns of antimicrobial drug resistance [86].

\section{Pelvic floor prolapse}

Pelvic floor dysfunction is defined as abnormal function of the pelvic floor and includes conditions that can have significant adverse impacts on a woman's quality of life, including UI (stress, urge, and mixed), fecal incontinence, pelvic organ prolapse, sexual dysfunction, diastasis recti abdominis, pelvic girdle pain, and chronic pain syndromes [87].

Pelvic organ prolapse (POP) is a hernia of the vaginal wall. Elements of vaginal hanging and perineum support undergo mechanical strains that lead to this pelvic floor disorder. The utero-sacral ligaments and the arcus tendineus of the pelvic fascia lose their elasticity. Atrophic levator ani muscles no longer provide elastic, active support. That is related to the aging of these 
structures but also to excessive mechanical strains pregnancy, delivery, dyschezia, physical practices. Moreover, postural disorders lead to a direct orientation of these strains on the genital slit [88].

Treatment should address the degree of discomfort and function limitation the patient is experiencing and any associated urinary or fecal incontinence. Asymptomatic patients do not require treatment unless ulceration becomes a problem.

Treatments include surgery, mechanical devices, and conservative management. Conservative management approaches, such as providing lifestyle advice and pelvic floor muscle training, are often used in cases of mild to moderate prolapse [89].

Surgical intervention remains the definitive treatment option for patients with symptomatic POP or stress urinary incontinence (SUI). In a large population-based study in the United States, the lifetime risk of any primary surgery for SUI or POP reaches $20 \%$ in women aged 80 years $[90,91]$.

\section{Vasomotor symptoms}

\section{Extended use of menopause hormone therapy}

Initiating systemic menopause hormone therapy (MHT) in women older than 60 years in general is not recommended. Discontinuation is typically suggested after 5 years or by the age of 60 . However, up to $8 \%$ of women continue to have hot flashes for 20 years or more after menopause [92]. A study of women's health across the nation (SWAN) revealed that African American women have the longest median duration of vasomotor symptoms, at 10.1 years, and Japanese and Chinese American women have the shortest, at 4.8 and 5.4 years, respectively [93].

The NAMS guideline from 2017 suggested that the recommendation to routinely discontinue systemic MHT after age 65 is not supported by data [94].

Although the American Geriatrics Society has issued warnings against the use of MHT in women over 65 years of age [95] two societies, the American College of Obstetricians and Gynecologists and the NAMS, suggest that the decision to continue or stop hormone therapy should include assessment of its risks and benefits, which may include relief from hot flashes, protection against bone loss, and preservation of quality of life $[94,96]$. The risks of MHT increase with age and duration of use and appear to be less marked in patients who take estrogen alone $[96,97]$.

\section{Discontinuation of menopause hormone therapy}

Controversy exists regarding how long MHT can be safely administered and when it should be discontinued [98]. Vasomotor symptoms (VMS) return in approx- imately $50 \%$ of women after discontinuation of hormone therapy, but data are lacking to directly compare the effects of abrupt discontinuation with those tapering over 3 to 6 months [99]. For recurrent, bothersome hot flashes, clinical experience supports a gradual taper, over 6 months to 1 year. However, protection against osteoporosis is lost rapidly with discontinuation [100].

Return of estrogen deficiency symptoms is common. In women who have recurrent VMS after stopping therapy, there is no reliable way to determine whether the symptoms will resolve quickly or persist for a prolonged time. For women who experience recurrent, bothersome hot flashes after stopping estrogen, Martin and Barbieri suggest initially nonhormonal options before considering resuming estrogen [101].

To summarize, after 3 to 5 years of menopause hormone therapy, there should be an attempt to taper and eventually discontinue treatment. If symptoms persist, lower doses or transdermal therapy could be offered, with periodic reevaluation of the risks and benefits. If vaginal moisturizers and lubricants are not sufficient for genitourinary symptoms after discontinuation of treatment, low-dose vaginal hormone therapy can be offered [98].

\section{Non-hormonal therapy}

For women complaining about VMS, menopausal hormone therapy (MHT) is recognized as the firstline therapy [102]; however, alternative treatments are needed in case of a contraindication to $\mathrm{MHT}$, adverse side effects, and poor compliance [103]. Additionally, there are also women who refuse hormonal treatment for a variety of reasons, mainly due to their fear of increasing the risk of cancer or weight gain [104, 105]. Hence, it is necessary to search for nonhormonal treatments that could be beneficial to women.

Paroxetine is an antidepressant drug which belongs to the SSRI (selective serotonin reuptake inhibitors) class. SSRIs such as citalopram or escitalopram were the first to be described as effective in reducing VMS severity [106]. In 2013, the United States Food and Drug Administration (US FDA) approved the use of lowdose paroxetine for the management of hot flushes and night sweats. In a systemic review from 2019 the authors concluded that low-dosage paroxetine can be useful in reducing VMS such as hot flushes in physiological or surgical postmenopausal women. However, additional studies are required to assess the efficacy of paroxetine on sleep disturbance [107].

As mentioned earlier, sleep disturbances increase around menopause, impacting the quality of life. When hormone replacement therapy is contraindicated, it is necessary to provide alternative treatments [108].

De Franciscis et al. in their study aimed to observe the effects of an herbal remedy from pollen extracts 
and soy isoflavones for menopausal complaints, particularly on sleep disorders. The authors concluded that non-hormonal treatments can effectively be used in symptomatic menopausal women: among these, after six months of treatment, pollen extracts might achieve a better improvement of hot flushes, sleep disturbances and menopause-related symptoms than soy isoflavones. The herbal remedy from pollen extracts is mainly effective when the quality of sleep is the most disturbing complaint [108].

In a recent review paper Genazzani et al. focused on a purified and specific cytoplasmic pollen extract, PureCyTonin, and its beneficial effects in the treatment of menopausal symptoms (e.g. hot flushes) in healthy women [109].

PureCyTonin is the main ingredient of the food supplement Serelys, which is a combination of purified pollen/pistil cytoplasmic extracts. The pollen and pistils come from selected plants belonging to the Gramineae family and/or Pinaceae family and are harvested separately using a standardized method [109].

Genazzani et al. concluded that Serelys is an effective and safe non-hormonal alternative for alleviating menopausal symptoms without increasing the risk of breast cancer in women in whom MHT is contraindicated or who do not wish to use hormones. Serelys has proven to be safe and efficacious. It improves hot flushes, sleep disturbances, and nervousness in menopausal women. These findings seem to correlate with the effect of its main ingredient, PureCyTonin, on inhibition of the reuptake of serotonin and other neurotransmitters [109].

Isoflavones are a group of naturally occurring compounds found in fruits, grains, and vegetables that are structurally similar to estrogen and have an affinity for estrogen receptors. These chemicals have been shown to elicit both estrogen-agonistic and estrogen-antagonistic properties when ingested orally in large quantities [110, 111].

Two specific dietary isoflavones, genistein and daidzein, are found in high concentrations in legumes such as soy, chickpeas, lentils, and red clover. Initial interest in these compounds for the management of VMS stemmed from the observation that Asian women, who traditionally consume large quantities of soy in their diet, appear to have lower rates of menopausal symptoms [110, 112].

A 2013 Cochrane meta-analysis was performed on 43 randomized, controlled studies of 4,084 patients to assess the efficacy and safety of food products, extracts, and supplements containing high levels of phytoestrogens in the amelioration of VMS in perimenopausal and postmenopausal women. The authors summarized that no conclusive evidence shows that phytoestrogen supplements effectively reduce the frequency or severity of hot flushes and night sweats in perimenopausal or postmenopausal women, although benefits derived from concentrates of genistein should be further investigated [110].

Various supplements that have been used in the management of VMS include Dioscorea villosa or wild yams, evening primrose, dong quai, American ginseng, kava kava, and St. John's wort. The evidence from clinical trials demonstrating benefit is conflicting and limited $[111,113,114]$. Therefore, current guidelines do not support the use of such agents at this time [111].

There has been a lot of conflicting information with regards to black cohosh, scientific name Actaea racemosa $\mathrm{L}$ (previously Cimicifugae racemosae), which has been used by Native Americans to treat malaria, impaired kidney function, sore throat, rheumatism, malaise, and menstrual irregularities [115]. The rhizome of black cohosh contains a number of biologically active constituents (including the triterpene glycosides actein and cimicifugoside, as well as fatty acids, resins, caffeic acids, isoferulic acids and isoflavones) [116], but the mechanism of action is unclear [111].

A 2012 Cochrane review [117] analyzed 16 randomized controlled trials of 2,027 perimenopausal or postmenopausal women treated with black cohosh using a median daily dose of $40 \mathrm{mg}$ for a mean duration of 23 weeks. There was no significant difference between black cohosh and placebo in the frequency of hot flashes. Data on safety were also inconclusive. The authors concluded that, at that time, there was insufficient evidence to support the use of black cohosh for menopausal symptoms. Black cohosh appears to have no effect on circulating luteinizing hormone, follicle-stimulating hormone, prolactin, or estradiol. A 52-week study reassuringly demonstrated that black cohosh does not increase endometrial thickness on ultrasound [118]. Reports of possible hepatotoxicity started to appear after 2000; however, after examining all reported cases, the US Pharmacopeial Convention's Dietary Supplements-Botanicals Expert Committee found only 30 reports possibly related to black cohosh. Eventually, the committee issued a directive that black cohosh products carry a warning statement: Discontinue use and consult a healthcare practitioner if you have a liver disorder or develop symptoms of liver trouble, such as abdominal pain, dark urine, or jaundice [111].

Additionally, the NAMS in the 2015 position statement on nonhormonal management of menopause stated that there are negative, insufficient, or inconclusive data suggesting that the following should not be recommended as proven therapies for managing VMS: cooling techniques, avoidance of triggers, exercise, yoga, paced respiration, relaxation, over-the-counter supplements and herbal therapies, acupuncture, calibration of neural oscillations, and chiropractic interventions [111]. Although there are many health benefits associated with the aforementioned therapies, attempts to use them are likely to delay receipt of more appropriate and effective 
therapies. In symptomatic women, such delays should be avoided given the association of VMS with other symptoms and overall quality of life [111].

Incorporating the available evidence into clinical practice will help ensure that women receive evidence-based recommendations along with appropriate cautions for appropriate and timely management of VMS [111].

\section{Conclusions}

Gynecologists can have a significant impact on the health of the elderly female patient as specialists and primary care physicians. Nowadays, most women spend more than one-third of their lives after menopause [92]. Therefore, there is plenty of opportunity for gynecologists to cater to the needs of postmenopausal women.

\section{Disclosure}

The authors report no conflict of interest.

\section{References}

1. Broker SA, Venugopalan PP, Bhat SN. Study of menopausal symptoms, and perceptions about menopause among women at a rural community in Kerala. J Midlife Health 2013; 4: 182-187.

2. Shwetha S, Minnalkodi N, Prasad G. Prevalence of gynecological diseases in postmenopausal women in tertiary care hospital in Chengalpattu district. Int J Reprod Contracept Obstet Gynecol 2020; 9: 3590-3595.

3. National Institutes of Health. National Institutes of Health State-of-the Science Conference statement: management of menopause-related symptoms. Ann Intern Med 2005; 142: 1003-1013.

4. Ostrowska A. Raport Polki 50 plus. Fundacja MSD dla Zdrowia Kobiet, Narodowy Instytut Zdrowia Publicznego Państwowy Zakład Higieny 2015.

5. Główny Urząd Statystyczny. Notatka z posiedzenia Sejmowej Komisji Polityki Senioralnej dotyczącej „Informacji Ministra Zdrowia na temat wpływu zmian demograficznych i starzenia się społeczeństwa na organizację systemu ochrony zdrowia i Narodowy Program Zdrowia" (19.02.2016 r.). Available at: http://www.stat.gov.pl.

6. Jacobsen LA, Kent M, Lee M, Mather M. America's Aging Population. Populatiom Reference Bureau 2011.

7. Stute P, Ceausu J, Depypere $\mathrm{H}$, et al. A model of care for healthy menopause and ageing: EMAS position statement. Maturitas 2016; 92: 1-6.

8. Utian W, Sultana C. Gynecologic care of the older woman. GLOWM 2008

9. Committee on Gynecologic Practice Opinion Number 755, October 2018. Obstetrics Gynecol 2018; 132: e181-e186.

10. Baill IC, Castiglioni A. Health maintenance in postmenopausal women. Am Fam Physician 2017; 95: 561-570.

11. Johnell O, Kanis J. Epidemiology of osteoporotic fractures. Osteoporos Int 2005; 16: S3-7.

12. Meng-Xia Ji, Qi Y. Primary osteoporosis in postmenopausal women. Chronic Dis Transl Med 2015; 1: 9-13.

13. Kling J, Clarke B, Sandhu N. Osteoporosis prevention, screening, and treatment: a review. J Womens Health (Larchmt) 2014; 23: 563-572.

14. Osterhoff A, Morgan E, Shefelbine SJ, et al. Bone mechanical properties and changes with osteoporosis. Injury 2016; 47: S11-S20.

15. Borgström F, Karlsson L, Ortsäter G, et al. Fragility fractures in Europe: burden, management and opportunities. Arch Osteoporos 2020; 15: 59.

16. Kanis JA. Assessment of osteoporosis at the primary health care level. In: WHO Scientific Group (ed.). WHO Scientific Group Technical Report. World Health Organization, 2007, 103
17. Svedbom A, Hernlund E, Ivergård M, et al. EU review panel of IOF. Osteoporosis in the European Union: a compendium of country-specific reports. Arch Osteoporos 2013; 8: 137.

18. Warriner AH, Patkar NM, Curtis JR, et al. Which fractures are most attributable to osteoporosis? J Clin Epidemiol 2011; 64: 46-53.

19. Fracture risk assessment tool (FRAX). Available at: https://www.sheffield.ac.uk/FRAX/.

20. U.S. Preventive Services Task Force. Osteoporosis: screening 2018. Available at: http://www.uspreventiveservicestaskforce.org/Page/Document/RecommendationStatementFinal/osteoporosis-screening Last accessed 19.10.2020

21. National Institute on Aging. Prevent falls and fractures. 2017. Available at: https://www.nia.nih.gov/health/prevent-falls-and-fractures.

22. Mozaffarian D, Benjamin EJ, Go AS, et al. American Heart Association Statistics Committee; Stroke Statistics Subcommittee. Heart disease and stroke statistics - 2016 update: a report from the American Heart Association. Circulation 2016; 133: e38-e360.

23. Eckel RH, Jakicic JM, Ard JD, et al. 2013 AHA/ACC guideline on lifestyle management to reduce cardiovascular risk: a report of the American College of Cardiology/American Heart Association Taskforce on Practice Guidelines. Circulation 2014; 129: S76-S99.

24. Arnett DFK, Blumenthal RS, Albert MA, et al. 2019 ACC/AHA Guideline on the Primary Prevention of Cardiovascular Disease: executive summary: a report of the American College of Cardiology/American Heart Association Task Force on Clinical Practice Guidelines. Circulation 2019; 140: e563-e595.

25. U. S. Preventive Services Task Force. Screening for type 2 diabetes mellitus in adults: U.S. Preventive Services Task Force recommendation statement. Ann Intern Med 2008; 148: 846-854.

26. Siu AL. On behalf of the U.S. Preventive Services Task Force Clinical Guidelines1 December 2015 Screening for Abnormal Blood Glucose and Type 2 Diabetes Mellitus: U.S. Preventive Services Task Force. Available at: https://doi.org/10.7326/M15-2345 Last accessed 17.10.2020.

27. Agency for Healthcare Research and Quality. Diagnosis and treatment of coronary heart disease in women: systematic reviews of evidence on selected topics. Rockville, Md.: Agency for Healthcare Research and Quality; 2003. Available at: http://www.ahcpr.gov/clinic/tp/chdwtoptp. htm.

28. U.S. Preventive Services Task Force. Statin use for the primary prevention of cardiovascular disease in adults: U.S. Preventive Services Task Force recommendation statement. JAMA 2016; 316: 1997-2007.

29. Stone NJ, Robinson JG, Lichtenstein AH, et al. American College of Cardiology/American Heart Association Task Force on Practice Guidelines. U.S. Preventive Services Task Force. Aspirin use to prevent cardiovascular disease and colorectal cancer: preventive medication. April 2016. Available at: http://www.uspreventiveservicestaskforce.org/Page/ Document/RecommendationStatementFinal/aspirin-to-prevent-cardiovascular-disease-and-cancer.

30. Oeffinger KC, Fontham ET, Etzioni R, et al. American Cancer Society. Breast cancer screening for women at average risk: 2015 guideline update from the American Cancer Society. JAMA 2015; 314: 1599-1614. Available at: http://www.uspreventiveservicestaskforce.org/Page/Document/ UpdateSummaryFinal/breast-cancer-screening1?ds=1\&amp;s=Breast.

31. U.S. Preventive Services Task Force. Breast cancer: screening. January 2016. Available at: http://www.uspreventiveservicestaskforce.org/Page/ Document/UpdateSummaryFinal/breast-cancer-screening1?ds $=1 \&$ amp;s=Breast.

32. USPSTF Final Recommendation Statement Breast Cancer: Screening January 11, 2016. Available at: https://www.uspreventiveservicestaskforce.org/uspstf/document/RecommendationStatementFinal/breastcancer-screening.

33. American College of Obstetricians-Gynecologists. Practice bulletin no. 179, July 2017 Breast Cancer Risk Assessment and Screening in AverageRisk Women. Available at: https://www.acog.org/clinical/clinical-guidance/practice-bulletin/articles/2017/07/breast-cancer-risk-assessmentand-screening-in-average-risk-women.

34. Available at: https://www.cancer.org/cancer/breast-cancer/screeningtests-and-early-detection/american-cancer-society-recommendationsfor-the-early-detection-of-breast-cancer.html.

35. U.S. Preventive Services Task Force. Breast cancer: medications for risk reduction. JAMA 2019; 322: 857-867. 
36. National Comprehensive Cancer Network. Breast cancer risk reduction [login required]. Available at: https://www.nccn.org/professionals/physician_gls/pdf/breast_risk.pdf.

37. Didkowska J, Wojciechowska U. Nowotwory złośliwe w Polsce w 2013 roku. Centrum Onkologii - Instytut im. M. Skłodowskiej-Curie, Warszawa 2015.

38. Alan Ö, Gürsel Ö, Ünsal M, Altın S, Kılçıksız S. Oncologic approach in geriatric patients. Okmeydanı Tıp Dergisi 2013; 29: 94-98.

39. Cinar D, Tas D. Cancer in the elderly. North Clin Istanb 2015; 2: 73-80.

40. American Cancer Society. Cancer Prevention \& Early Detection Facts \& Figures 2019-2020. Available at: https://www.cancer.org/content/dam/ cancer-org/research/cancer-facts-and-statistics/cancer-preventionand-early-detection-facts-and-figures/.

41. American Cancer Society July 2020. Available at: https://www.cancer. org/cancer/cervical-cancer/detection-diagnosis-staging/cervical-cancer-screening-guidelines.html\#references.

42. U.S. Preventive Services Task Force. Cervical cancer: screening August 2018. Available at: https://www.uspreventiveservicestaskforce.org/ uspstf/document/RecommendationStatementFinal/cervical-cancerscreening RecommendationStatementFinal/cervical-cancer-screening.

43. Huh WK, Ault KA, Chelmow D, Davey DD. Use of primary high-risk human papillomavirus testing for cervical cancer screening: interim clinical guidance. Obstet Gynecol 2015; 125: 330-337.

44. Ferlay J, Soerjomataram I, Dikshit R, et al. Cancer incidence and mor tality worldwide: sources, methods and major patterns in GLOBOCAN 2012. Int J Cancer 2015; 136: E359-386.

45. Vitale SG. Hysteroscopic management of intrauterine pathologies in postmenopause. Climacteric 2020; 23: 319-320.

46. Van Hanegem N, Breijer MC, Khan KS, et al. Diagnostic evaluation of the endometrium in postmenopausal bleeding: an evidence-based approach. Maturitas 2011; 68: 155-164.

47. Clarke MA, Long BJ, Del Mar Morillo A, Arbyn M, Bakkum-Gamez JN, Wentzensen N. Association of endometrial cancer risk with postmenopausal bleeding in women: a systematic review and meta-analysis. JAMA Intern Med 2018; 178: 1210-1222.

48. Van Hanegem N, Prins MM, Bongers MY, et al. The accuracy of endometrial sampling in women with postmenopausal bleeding: a systematic review and meta-analysis Eur J Obstet Gynecol Reprod Biol 2016; 197: 147-155.

49. ACOG Committee Opinion No. 734: the role of transvaginal ultrasonography in evaluating the endometrium of women with postmenopausa bleeding. Obstet Gynecol 2018; 131: e124-e129.

50. Garcia A. Office hysteroscopic evaluation of postmenopausal bleeding OBG Manag 2019; 31: 36-42.

51. Kolhe S. Management of abnormal uterine bleeding - focus on ambulatory hysteroscopy. Int J Womens Health 2018; 22: 127-136.

52. ACOG technology assessment no. 13 summary: hysteroscopy. Obstet Gynecol 2018; 131: 1.

53. Centini G, Troia L, Lazzeri L, Petraglia F, Luisi S. Modern operative hysteroscopy. Minerva Ginecol 2016; 68: 126-132.

54. Available at: https://www.cancer.net/cancer-types/colorectal-cancer/ statistics.

55. Keane $M$, Johnson GJ. Early diagnosis improves survival in colorectal cancer. Practitioner 2012; 256: 15-18, 2.

56. American Cancer Society Guidelines. Available at: https://www.cancer org/health-care-professionals/american-cancer-society-preventionearly-detection-guidelines/colorectal-cancer-screening-guidelines.html.

57. U.S. Preventive Services Task Force. Colorectal cancer: screening. June 2016. Available at: http://www.uspreventiveservicestaskforce.org/ Page/Document/UpdateSummaryFinal/colorectal-cancer-screening2? ds=1\&amp;s=colorectal\%20cancer.

58. Granville L, Pregler J. Women's sexual health and aging. J Am Geriatr Soc 2018; 66: 595-601.

59. England PH. Table 2: new STI diagnoses and rates by gender, sexual risk, age group and ethnic group, 2014 to 2018. Public Health England, London 2019

60. Sherman CA, Harvey SM, Noell J. Are they still having sex? STI's and unintended pregnancy among mid-life women. J Women Aging 2005; 17: 41-55.

61. Lewis $\mathrm{R}$, Mitchell KR, Mercer $\mathrm{CH}$, et al. Navigating new sexual partnerships in midlife: a socioecological perspective on factors shaping ST risk perceptions and practices. Sex Transm Infect 2020; 96: 238-245.
62. Dalrymple J, Booth J, Flowers P, et al. Socio-cultural influences upon knowledge of sexually transmitted infections: a qualitative study with heterosexual middle-aged adults in Scotland. Reprod Health Matters 2016; 24: 34-42.

63. Fileborn B, Brown G, Lyons A, et al. Safer sex in later life: qualitative interviews with older Australians on their understandings and practices of safer sex. J Sex Res 2018; 55: 164-177.

64. Smith KP, Christakis NA. Association between widowhood and risk of diagnosis with a sexually transmitted infection in older adults. Am J Public Health 2009; 99: 2055-2062.

65. U.S. Preventive Services Task Force. Sexually transmitted infections: behavioral counselling. August 18, 2020. Available at: https://www.uspreventiveservicestaskforce.org/uspstf/document/RecommendationStatementFinal/sexually-transmitted-infections-behavioral-counseling.

66. Portman DJ, Gass ML. Genitourinary syndrome of menopause: new terminology for vulvovaginal atrophy from the International Society for the Study of Women's Sexual Health and the North American Menopause Society. Vulvovaginal Atrophy Terminology Consensus Conference Panel. Menopause 2014; 21:1063-1068.

67. Moral E, Delgado JL, Carmona F, et al. Genitourinary syndrome of menopause. Prevalence and quality of life in Spanish postmenopausal women. The GENISSE study. Climacteric 2018; 21:167-173.

68. Alvisi S, Gava G, Orsili I, et al. Vaginal health in menopausal women. Medicina (Kaunas) 2019; 55: 615.

69. The 2020 genitourinary syndrome of menopause position statement of The North American Menopause Society (NAMS). Menopause 2020; 27: 976-992.

70. Nappi RE, Palacios S. Impact of vulvovaginal atrophy on sexual health and quality of life at postmenopause. Climacteric 2014; 17: 3-9.

71. Phillips NA, Bachmann GA. Genitourinary syndrome of menopause: common problem, effective treatments. Clin J Med 2018; 85: 390-398.

72. Erekson EA, Yip SO, Wedderburn TS, et al. The Vulvovaginal Symptoms Questionnaire: a questionnaire for measuring vulvovaginal symptoms in postmenopausal women. Menopause 2013; 20: 973-979.

73. Gabes M, Knüttel H, Stute P, Apfelbacher CJ. Measurement properties of patient-reported outcome measures (PROMs) for women with genitourinary syndrome of menopause: a systematic review. Menopause 2019; 26: $1342-1353$.

74. Robinson D, Toozs-Hobson P, Cardozo L. The effect of hormones on the lower urinary tract. Menopause Int 2013; 19: 155-162.

75. Ptak M, Brodowska A, Ciećwież S, Rotter I. Quality of life in women with stage 1 stress urinary incontinence after application of conservative treatment - a randomized trial. Int J Environ Res Public Health 2017; 14: 577.

76. Abrams P, Cardozo L, Fall M, et al. Standardisation Sub-committee of the International Continence Society. The standardisation of terminology of lower urinary tract function: report from the Standardisation Subcommittee of the International Continence Society. Neurourol Urodyn 2002; 21: 167-178

77. Shifren JL, Gass MLS. The North American Menopause Society recommendations for clinical care of midlife women. Menopause 2014; 21 : 1038-1062.

78. Gandhi J, Chen A, Dagur G, et al. Genitourinary syndrome of menopause: an overview of clinical manifestations, pathophysiology, etiology, evaluation, and management. Am J Obstet Gynecol 2016; 215: 704-711.

79. Palacios S, Mejía A, Neyro JL. Treatment of the genitourinary syndrome of menopause. Climacteric 2015; 18: 23-29.

80. Townsend MK, Resnick NM, Grodstein F. Caffeine intake and risk of urinary incontinence progression among women. Obstet Gynecol 2012; 119: 950-957.

81. Syan R, Brucker BM. Guideline of guidelines: urinary incontinence. BJU Int 2016; 117: 20-33.

82. Geng H, Cobussen Boekhorst H, Farrel J, et al. Catheterization, indwelling catheters in adults, urethral and suprapubic - evidence based guidelines for best practice in urological health care. Edition presented at the $13^{\text {th }}$ International EAUN Meeting, Paris. Arnhem: EAUN Office, 2012. Available at: http://www.guideline.gov/content.aspx?id=36631.

83. Auwad W, Steggles P, Bombieri L, Waterfield M, Wilkin T, Freeman R. Moderate weight loss in obese women with urinary incontinence: a prospective longitudinal study. Int Urogynecol J Pelvic Floor Dysfunct 2008; 19: 1251-1259. 
84. Raz R. Urinary tract infection in postmenopausal women. Korean J Urol 2011; 52: 801-808.

85. Hicking D, Tung-Tien, Xue-Ru W. Anatomy and physiology of the urinary tract: relation to host defense and microbial infection. Microbiol Spectr 2015; 3: 10.

86. Kim H-K, Kang S-Y, Chung Y-J, Kim J-H, Kim M-R. The recent review of the genitourinary syndrome of menopause. J Menopausal Med 2015; 21: 65-71.

87. Lawson S, Sacks AJ. Pelvic floor physical therapy and women's health promotion. J Midwifery Womens Health 2018; 63: 410-417.

88. Mezzadri M. Pelvic organ prolapse physiopathology. Rev Prat 2019; 69: 385-386.

89. Hagen S, Stark D. Conservative prevention and management of pelvic organ prolapse in women. Cohrane Database Syst Rev 2011; 12: CD003882.

90. Wu JM, Matthews CA, Conover MM, Pate V, Jonsson Funk M. Lifetime risk of stress urinary incontinence or pelvic organ prolapse surgery. Obstet Gynecol 2014; 123:1201-1206.

91. Akın $Y$, Young $M$, Elmussareh $M$, et al. The novel and minimally invasive treatment modalities for female pelvic floor muscle dysfunction. Beyond the traditional. Balkan Med J 2018; 35: 358-366.

92. Zeleke BM, Davis SR, Fradkin P, Bell RJ. Vasomotor symptoms and urogenital atrophy in older women: a systematic review. Climacteric 2015; 18: 112-120.

93. Avis NE, Crawford SL, Greendale G, et al. Duration of menopausal vasomotor symptoms over the menopause transition. JAMA Intern Med 2015; 175: 531-539.

94. The NAMS 2017 Hormone Therapy Position Statement Advisory Panel. The 2017 hormone therapy position statement of the North American Menopause Society. Menopause 2017; 24: 728-753.

95. American Geriatrics Society. 2012 Beers Criteria Update Expert Panel. American Geriatrics Society updated Beers Criteria for potentially inappropriate medication use in older adults. J Am Geriatr Soc 2012; 60: 616-631.

96. Kaunitz AM. Extended duration use of menopausal hormone therapy. Menopause 2014; 21: 679-681.

97. Manson JE, Chlebowski RT, Stefanick ML, et al. Menopausal hormone therapy and health outcomes during the intervention and extended poststopping phases of the Women's Health Initiative randomized trials. JAMA 2013; 310: 1353-1368.

98. Pinkerton JA. Hormone therapy for postmenopausal women. N Engl J Med 2020; 382: 446-455.

99. Grady D, Sawaya GF. Discontinuation of postmenopausal hormone therapy. Am J Med 2005; 118: 163-165.

100. The NAMS 2017 Hormone Therapy Position Statement Advisory Panel. The 2017 hormone therapy position statement of the North American Menopause Society. Menopause 2017; 24: 728-753.

101. Available at: https://www.uptodate.com/contents/treatment-of-menopausal-symptoms-with-hormone-therapy\#H2879661593.

102. Krause MS, Nakajima ST. Hormonal and nonhormonal treatment of vasomotor symptoms. Obstet Gynecol Clin 2015; 42: 163-179.

103. Chang HY, Jotwani AC, Lai YH, et al. Hot flashes in breast cancer survivors: frequency, severity and impact. Breast 2016; 27: 116-121.

104. De Franciscis, P, Cobellis, L, Fornaro, F, Sepe, E, Torella, M, Colacurci, N. Low-dose hormone therapy in the perimenopause. Int J Gynaecol Obstet 2007; 98: 138-142.

105. Laganà AS, La Rosa VL, Rapisarda AMC, et al. Anxiety and depression in patients with endometriosis: Impact and management challenges. Int J Womens Health 2017; 9: 323-330.

106. Stubbs C, Mattingly L, Crawford SA, et al. Do SSRIs and SNRIs reduce the frequency and/or severity of hot flashes in menopausal women. State Med Assoc 2017; 110: 272-274.

107. Riemma G, Schiattarella A, La Verde M, et al. Efficacy of low-dose paroxetine for the treatment of hot flushes in surgical and physiological postmenopausal women: systematic review and meta-analysis of randomized trials. Medicina (Kaunas) 2019; 55: 554.

108. De Franciscis P, Conte A, Schiattarella A, Riemma G, Cobellis L, Colacurci N. Non-hormonal treatments for menopausal symptoms and sleep disturbances: a comparison between purified pollen extracts and soy isoflavones. Curr Pharm Des 2020; 26: 4509-4514.
109. Genazzani A, Panay N, Simoncini T, et al. Purified and specific cytoplasmic pollen extract: a non-hormonal alternative for the treatment of menopausal symptoms. Gynecol Endocrinol 2020; 36: 190-196.

110. Lethaby AE, Brown J, Marjoribanks J, et al. Phytoestrogens for vasomotor menopausal symptoms. Cochrane Database Syst Rev 2007; (4): CD001395.

111. Nonhormonal management of menopause-associated vasomotor symptoms: 2015 position statement of the North American Menopause Society. Menopause N Y N. 2015; 22: 1155-1172.

112. ACOG Practice Bulletin No. 141: management of menopausal symptoms. Obstet Gynecol 2014; 123: 202-216.

113. Borrelli F, Ernst E. Alternative and complementary therapies for the menopause. Maturitas 2010; 66: 333-343.

114. Wylie-Rosett J. Menopause, micronutrients, and hormone therapy. Am J Clin Nutr 2005; 81: 1223S-1231S

115. Blumenthal M. The ABC Clinical Guide to Herbs. American Botanical Council, Austin 2003.

116. Mills S, Bone K. Principles and Practice of Phytotherapy: Modern Herbal Medicine. Churchill Livingstone, Edinburgh 2000.

117. Leach MJ, Moore V. Black cohosh (Cimicifuga spp.) for menopausal symptoms. Cochrane Database Syst Rev 2012; 2012: CD007244.

118. Raus K, Brucker C, Gorkow C, Wuttke W. First-time proof of endometrial safety of the special black cohosh extract (Actaea or Cimicifuga racemosa extract) CR BNO 1055. Menopause 2006; 13: 678-691. 